\title{
CHARACTERISTICS OF THE STRUCTURE OF ACTUAL STATE OF FORESTS AND FORECAST OF ITS PROBABLE DEVELOPMENT ON THE TERRITORY OF GOLD MINING (REPRESENTED BY GOLD EXPLORATION AREA IN IRKUTSK REGION)
}

\author{
Alexander Sizykh ${ }^{1 *}$, Victor Voronin ${ }^{1}$, Ruslan Moritz ${ }^{1}$, Mikhail Pastukhov $^{2}$, Vera Poletaeva ${ }^{2}$ \\ ${ }^{1}$ Siberian Institute of Plant Physiology and Biochemistry SB RAS, 664033, \\ Irkutsk, Lermontova str., 132, Russia; \\ ${ }^{2}$ Vinogradov Institute of Geochemistry SB RAS, 664033, \\ Irkutsk, Favorsky str., 1A, Russia;
}

*Corresponding Author Alexander Sizykh, e-mail: alexander.sizykh@gmail.com;

Received November 2019; Accepted December 2019; Published January 2020;

DOI: https://doi.org/10.31407/ijees10.105

\begin{abstract}
The research was performed within a requirements specification concerning ecological monitoring of main components in the ecosystems aimed to assessment of available and potential impact of a gold exploring enterprise in one of gold mining areas onto the environment in Irkutsk Region (East Siberia). While performing it, normative and methodological documents as they are nowadays were taking into consideration. While studying initial state of ecosystems components, we assessed first of all the role of natural regional factors and the degree of possible anthropogenic impact onto the environment. Main limiting factors for the enterprise extension in this area may be available here functionally important forest coenoses. Their functions are: protection from erosion, environment formation and water protection. The forests forming basic cover of the studied territory are related to the first group and are in the same time zones of nuts collection in the region. Structural-dynamic organization and formation vector of forests on the enterprise territory and in its environments are most important parameters reflecting the actual state of the environment. Due to this fact, we performed a geobotanic survey to reveal coenoses typology and their structural coenotic peculiarities in different sites of forests coenoses formation. The results obtained due to this research allow to represent the peculiarities of spatial-temporal variation of forests, the degrees of their actual and probable transformation at increase of anthropogenic impact onto the environment within the licensed site. Such data may serve as a base for possible under the present condition's reconstitution activities aimed to prevention of potentially negative impact onto the vegetation at further exploration of the licensed territory.
\end{abstract}

Key words: vegetation structure, spatial-temporal variability of forests, forecast of forests formation, gold mining, Irkutsk Region 